\title{
A COMPARATIVE STUDY OF HUMAN THERMAL COMFORT CONDITIONS IN TWO MOUNTAINOUS REGIONS IN GREECE DURING SUMMER
}

\author{
A. KAMOUTSIS ${ }^{1}$ \\ A. MATSOUKIS ${ }^{1, *}$ \\ K. CHRONOPOULOS ${ }^{2}$ \\ E. MANOLI ${ }^{1}$
}

\author{
${ }^{1}$ Laboratory of General and Agricultural Meteorology \\ Division of Geological Sciences and Atmospheric Environment \\ Department of Sciences, Agricultural University of Athens \\ 75, lera Odos Str., 11855 Athens, Greece \\ ${ }^{2}$ Laboratory of Physics, Division of Chemical and Physical Sciences, \\ Department of Sciences \\ Agricultural University of Athens \\ 75, lera Odos Str., 11855 Athens, Greece
}

Received: 09/03/09

Accepted: 26/05/09 *to whom all correspondence should be addressed: e-mail: armatsoukis@aua.gr

\begin{abstract}
Human thermal comfort conditions were determined in two mountainous regions of Greece, Gerania mountains (MG) in east continental Greece, and mountainous Nafpaktia (MN) in west continental Greece. Both regions are unexploited with considerable tourist potential. Four sites in each study region were selected on the basis of different altitude. Air temperature and humidity, $1.5 \mathrm{~m}$ above ground surface, were recorded simultaneously every 15 minutes by sensors with dataloggers in selected sites between 23 June and 28 August 2007. Data of the above parameters were used for the calculation of the thermohygrometric index from which thermal comfort conditions were evaluated. Also, an artificial neural network model, was applied for the THI values evaluation at the highest examined altitudes based on the respective values of the lowest examined altitudes in both MG and MN. Results showed that from 09:00 to 20:00 h, MN was found to be more suitable, in relation to MG, for tourist and recreation activities at altitudes of $1338 \mathrm{~m}$. At lower altitudes, both study regions could be proposed in an equal basis for the above activities during summer. Also, for the same period, thermal comfort conditions at the highest examined altitudes of MN and MG can accurately be predicted using artificial neural network models on the basis of those at lowest examined altitudes. From 21:00 to $08: 00 \mathrm{~h}, \mathrm{MN}$ can be considered clearly as a better tourist destination than MG.
\end{abstract}

KEYWORDS: thermohygrometric index, artificial neural networks, mountainous Nafpaktia, Gerania mountains.

\section{INTRODUCTION}

Mountains are integral and important parts of the climate system (Beniston et al., 1997). Meteorological factors such as the solar radiation, the air temperature and the humidity in combination with the intense relief, different slopes, orientations and other topographic irregularities results in a variety of microclimates in mountain regions (Barry, 2001). Mountains are, in general, one of the most popular destinations for tourists (Nepal and Chipeniuk, 2005).

The air layer conditions near the ground up to $2.0 \mathrm{~m}$ affect strongly the human activities (Yilmaz et al., 2007) which are related closely with thermal comfort conditions. Thermal comfort is defined as a condition of mind in which satisfaction is expressed with thermal environment (ASHRAE, 1966; Oliveira and Andrade, 2007).

One procedure for the assessment of thermal comfort conditions is based on the use of biometeorological indices (Matzarakis, 2007) which usually require multi-variants (Toy et al., 2007). A relative index, the thermohygometric index (THI) provides a more detailed approach to summer thermal comfort conditions in mountain areas when the available data are air temperature and 
humidity (Kamoutsis et al., 2007; Manoli, 2008). The optimum THI values in which people are in comfortable conditions, occurs between 15.0 and $19.9^{\circ} \mathrm{C}$ (Toy et al., 2007).

This study focuses on the comparison of thermal comfort conditions between two mountain regions of Greece, Gerania mountains and mountainous Nafpaktia in order to determine the more suitable region for tourist activities.

\section{MATERIALS AND METHODS}

\subsection{Study regions and measurement sites}

The first study region is Gerania mountains (highest summit $1341 \mathrm{~m}$ ) which are located in east continental Greece (Figure 1), about $60 \mathrm{Km}$ away from Athens, the metropolitan urban centre of Greece. The eastern part of Gerania belongs to the Prefecture of West Attica and the western one to the Prefecture of Korinthia and whole region is included in the Natura 2000 network (Manoli, 2008). The presence of dense forests with Pinus halepensis in lower and Abies cephalonica in higher altitudes, at a good conservation status, creates a natural environment of great aesthetic value and of utmost ecological importance. This is strengthened by the fact of the location of the eastern Gerania to the west Attica, a region heavily aggravated by the existing industrial activity. The region of Gerania mountains (MG) is unexploited, abandoned and no industrial activities are present. It appears to have a great potential for recreation and tourist activities because of its relatively small distance of Athens combined with the possibility to accept a noticeable percentage of Athens population.

The second study region is located on a wide part of mountainous Nafpaktia districts (MN), with altitudes ranged from 676 to $1338 \mathrm{~m}$ (Figure 1) in the Prefecture of Aitoloakarnania, in west continental Greece, about $350 \mathrm{Km}$ away from Athens. The evergreen dense fir (Abies sp.) forests which dominate in the zone of conifers, the various evergreen broadleaved plant species at lower altitudes, the diverse relief and the presence of Evinos River along with many small springs indicate an amenity-rich region with noticeable ecological value. In this region, few commercial, industrial or other human activities are performed and it could be a potentially ideal destination for recreation and tourism for people from various urban centers of West Greece and not only.

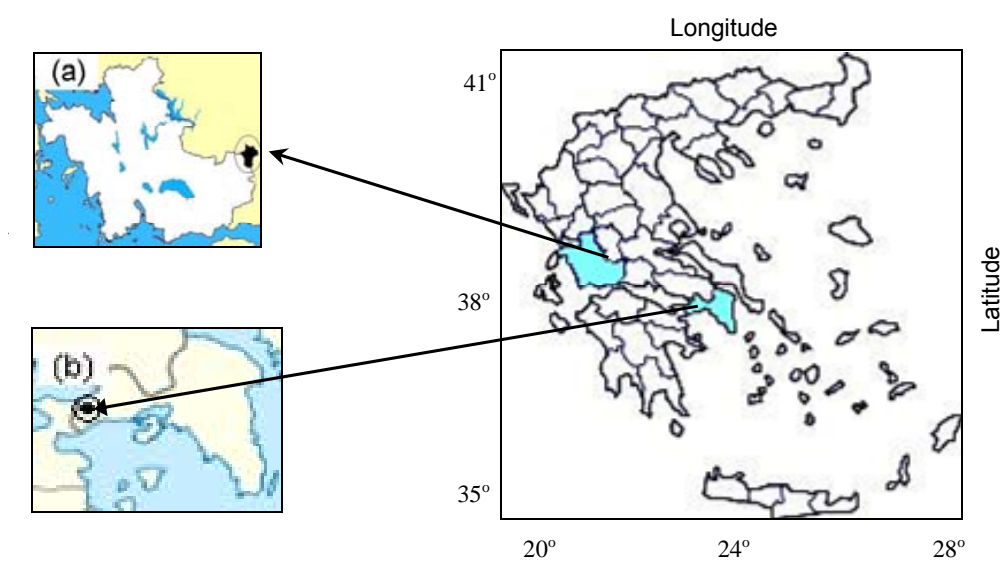

Figure 1. (a): Mountainous Nafpaktia and (b): Gerania mountains (regions with black color inside the circle)

Four sites of the same orientation (SW) in each study region were selected. The selection was mainly based on different altitude. There were four levels, each with similar altitudes, for both study regions. The fist level comprised the altitudes (alt.) 650 and $676 \mathrm{~m}$, the second level alt. 860 and 862 $\mathrm{m}$, the third level alt. 1050 and $1082 \mathrm{~m}$ and the fourth level alt. 1334 and $1338 \mathrm{~m}$ (Table 1). The orientation, the altitude, the latitude and the longitude of each site were evaluated using a mobile Global Positioning System (Garmin eTrex Vista) and checked against with 1:50000 topographic maps.

The mean values of average, maximum and minimum air temperatures were $27.1,30.8$ and $21.9{ }^{\circ} \mathrm{C}$ from the nearby meteorological station (Korinthos, $37^{\circ} 56^{\prime} \mathrm{N}, 22^{\circ} 57^{\prime} \mathrm{E}$, altitude $14.4 \mathrm{~m}$ ) to MG (distance $17.0 \mathrm{Km}$ ), during the period July-August from 1970 to 1984. The respective values of the previous parameters were $24.7,31.0$ and $16.4^{\circ} \mathrm{C}$ from the nearby meteorological station (Lidoriki, 
$38^{\circ} 31^{\prime} \mathrm{N}, 22^{\circ} 08^{\prime} \mathrm{E}$, altitude $600.0 \mathrm{~m}$ ) to MN (distance $25.0 \mathrm{Km}$ ), during the same period from 1975 to 1995 (Hellenic National Meteorological Service, 1999). The mean values of average and minimum air temperatures were higher in Korinthos compared to Lidoriki.

Table 1. Study sites in Gerania mountains and mountainous Nafpaktia

\begin{tabular}{|c|c|c|c|c|c|c|}
\hline & Altitude (m) & Latitude & & Longitude & & $\begin{array}{l}\text { Dominating } \\
\text { vegetation }\end{array}$ \\
\hline \multicolumn{7}{|c|}{ Gerania mountains } \\
\hline s1 & 650 & $38^{\circ} 00^{\prime} 59.2^{\prime \prime}$ & $\mathrm{N}$ & $23^{\circ} 10^{\prime} 58.5^{\prime \prime}$ & $E$ & Pinus halepensis \\
\hline s2 & 860 & $38^{\circ} 00^{\prime} 51.1^{\prime \prime}$ & $\mathrm{N}$ & $23^{\circ} 10^{\prime} 18.7^{\prime \prime}$ & $E$ & Pinus halepensis \\
\hline s3 & 1050 & $38^{\circ} 01^{\prime} 04.7^{\prime \prime}$ & $\mathrm{N}$ & $23^{\circ} 09^{\prime} 23.2^{\prime \prime}$ & $E$ & $\begin{array}{l}\text { Pinus halepensis, } \\
\text { Abies cephalonica }\end{array}$ \\
\hline s4 & 1334 & $38^{\circ} 01^{\prime 1} 16.0^{\prime \prime}$ & $\mathrm{N}$ & $23^{\circ} 08^{\prime} 02.4^{\prime \prime}$ & $E$ & Abies cephalonica \\
\hline \multicolumn{7}{|c|}{ mountainous Nafpaktia } \\
\hline s5 & 676 & $38^{\circ} 43^{\prime} 05.1^{\prime \prime}$ & $\mathrm{N}$ & $21^{\circ} 57^{\prime} 36.8^{\prime \prime}$ & $E$ & $\begin{array}{l}\text { Abies cephalonica, } \\
\text { Cercis siliquastrum, } \\
\text { Pistacia terebinthus }\end{array}$ \\
\hline s6 & 862 & $38^{\circ} 42^{\prime} 40.9^{\prime \prime}$ & $\mathrm{N}$ & $21^{\circ} 57^{\prime} 50.1^{\prime \prime}$ & $E$ & Abies cephalonica \\
\hline s7 & 1082 & $38^{\circ} 42^{\prime} 28.9^{\prime \prime}$ & $\mathrm{N}$ & $21^{\circ} 57^{\prime} 50.4^{\prime \prime}$ & $E$ & $\begin{array}{l}\text { Abies cephalonica, } \\
\text { Juniperus sp. }\end{array}$ \\
\hline s8 & 1338 & $38^{\circ} 44^{\prime} 29.5^{\prime \prime}$ & $\mathrm{N}$ & $21^{\circ} 58^{\prime} 34.2^{\prime \prime}$ & $E$ & Abies cephalonica \\
\hline
\end{tabular}

\subsection{Measurements and quantification of thermal conditions}

Air temperature and humidity, $1.5 \mathrm{~m}$ above soil surface, were monitored simultaneously every 15 minutes by sensors with dataloggers (Hobo type Pro, H08-032-08, accuracy $\pm 0.2{ }^{\circ} \mathrm{C}$ at $25{ }^{\circ} \mathrm{C}$ and $\pm 3 \% \mathrm{RH}$ over $0{ }^{\circ} \mathrm{C}$ to $50{ }^{\circ} \mathrm{C}$ ), one for each site, for the summer period between 23 June and 28 August 2007. During this period three heat wave spells were detected in Greece. It is noted that the mean, maximum and minimum air temperature values during the period of July-August 2007 at the region of Votanikos (Agricultural University of Athens) were higher by $1.2{ }^{\circ} \mathrm{C}, 1.5^{\circ} \mathrm{C}$ and $0.1{ }^{\circ} \mathrm{C}$, respectively, in relation to normal values (1991-2006 base period). The data loggers were enclosed in appropriate shelters screened from rainfall and direct solar radiation. The form of the shelters allowed acceptable air ventilation.

For air temperature and humidity data, means on hourly basis were calculated for each study site and for the whole experimental period. These means were used for the calculation of the average hourly values of thermohygrometric index (THI), a widely used biometeorological index (Toy et al., 2007), according to the equation:

$\mathrm{THI}\left({ }^{\circ} \mathrm{C}\right)=\mathrm{t}-[(0.55-0.0055 \mathrm{f})(\mathrm{t}-14.5)]$

where $t=a i r$ temperature $\left({ }^{\circ} \mathrm{C}\right)$ and $\mathrm{f}=$ relative humidity $(\%)$. The selection of the previous index was based on its suitability to provide a more detailed approach of summer biometeorological conditions in relation to other examined indices in mountainous areas (Kamoutsis et al., 2007; Manoli, 2008), by using the available data set. The above THI values were used for the evaluation of human thermal comfort (Table 2) as modified from Toy et al. (2007).

Table 2. Relation of human thermal comfort with thermohygrometric index (THI)

\begin{tabular}{lc}
\hline Human thermal comfort class & THI value $\left({ }^{\circ} \mathrm{C}\right)$ \\
\hline Cold & -1.7 to +12.9 \\
\hline Cool & +13.0 to +14.9 \\
\hline Comfortable & +15.0 to +19.9 \\
\hline Hot & +20.0 to +26.4 \\
\hline Very hot & +26.5 to +29.9 \\
\hline
\end{tabular}




\subsection{Statistical analysis}

The relative frequencies of $\mathrm{THI}$ different classes were calculated on hourly basis for the whole examined period. A lot of people suffer from unfavourable biometeorological conditions, that is to say THI values laying above "Comfortable" class, during the summer months in Greece. Taking this into consideration, and in order to compare MG and MN with regard to "Hot" and "Very Hot" classes, their hourly relative frequencies were converted to percentages and their sum was calculated for two equal periods of each day. The first period was extended from 9:00 up to 20:00 $\mathrm{h}$ and the second comprised the rest hours $(21: 00$ up to $8: 00 \mathrm{~h})$. For each hour, the previous sum was the average term of 67 values (each value corresponds to each experimental day). The data of percentages were arranged in pairs, since there is a value of each percentage for each study region and hour, separately for each period and level and the two-sample $t$ test was applied. The paired differences of calculated percentages were subjected to angular transformation for meeting the assumption of normality, prior to statistical analysis.

\subsection{Model description}

Meteorological stations network is sparse in mid and high altitudes of mountain regions due mainly to the difficulty of installing and maintaining its instruments. Therefore, researchers are often forced to evaluate the meteorological conditions from data collected in nearby lower altitude sites (Friedland et al., 2003; Tang and Fang, 2006). In this study, a most commonly used artificial neural network model, the multilayer perceptron $(M L P)$ was used for the THI values evaluation at fourth level of altitudes based on the respective values of the first level in MG and MN. A recent study showed that MLP models can effectively be used to evaluate microclimate conditions in remote mountainous canyons (Chronopoulos et al., 2008).

For the MLP model, the output with one hidden layer is given by:

$$
f(x)=\phi^{s}\left(\sum_{i=1}^{I} w_{i s} \phi^{i}\left(\sum_{e=1}^{n} w_{e i} x_{e}+w_{0}\right)+w_{s}\right)
$$

where $I$ is the number of hidden nodes, $n$ is the number of input variables, $w_{e i}$ and $w_{i s}$ are the weights of the input-to-hidden and hidden-to-output layer, $w_{0}$ and $w_{s}$ are the corresponding thresholds (bias), $\phi^{i}$ and $\phi^{s}$ are the units' activation functions (Rumelhart et al., 1986a).

For MLP training, the backpropagation algorithm was used, which is the most frequently used algorithm for training (Rumelhart et al., 1986b). The activation function for the hidden units as well as the output unit is the logistic sigmoid function $\phi(x)=\left(1+e^{-x}\right)^{-1}$. A trial-and-error approach was also applied to select the best network architecture. One hidden layer with various numbers of nodes formed each network. The training set consisted of $1 / 2$ of the data, the selection set of $1 / 4$ of the data and the test set of the remaining $1 / 4$ of the data, randomly assigned.

In our study, three prediction scenarios have been tested. In the first one (T1), the inputs were the temperature and the relative humidity of the sites of the first level ( 11 at MG and s5 at MN), while the output was the temperature and the relative humidity for the sites of the fourth level (s4 at MG and $\mathrm{s} 8$ at $\mathrm{MN}$ ). The THI factor was then computed according to the equation (1). In the second scenario (T2), the input was the THI values of the first level and the output the THI values of the fourth level. In the third prediction scenario (T3), the inputs were the temperature and the relative humidity of the first level altitudes, and the output was the THI values of the sites at the fourth level. Results were considered significant at $\mathrm{p}<0.05$.

\section{RESULTS AND DISCUSSION}

Human thermal comfort conditions as expressed through the relative frequencies of different classes of THI values per hour at the examined levels for MN and MG are presented in Figure 2. Totally, five classes of THI values (Very hot, hot, comfortable, cool and cold) were found.

At the first level (alt. $676 \mathrm{~m}$ in $\mathrm{MN}$ and $650 \mathrm{~m}$ in MG) from 9:00 to 20:00 h, the majority of THI values in MN (85.3\%) and MG (91.2\%) was classified as "Hot". The situation was different at night and morning hours $(21: 00-8: 00 \mathrm{~h}$ ), where a large percentage of the THI values, totally $89.5 \%$, occupied the "Comfortable", "Cool" and "Cold" classes in MN. The "Comfortable" class obtained $61.4 \%$ in MG the previous hours (Figure 2a, b). 
At the second level (alt. $862 \mathrm{~m}$ in $\mathrm{MN}$ and $860 \mathrm{~m}$ in MG), a noticeable percentage of THI values was lying in the "Hot" class in both study regions during the period 09:00 -20:00 h (Table 3). On the other hand, THI values were in the "Comfortable" class in $11.7 \%(\mathrm{MN})$ and $16.3 \%$ (MG) during the same period. For the rest period of the day (21:00-08:00 h), THI values were classed as "Comfortable" at about $74.0 \%$ in both MN and MG while $11.8 \%$ and $3.9 \%$ of these values were detected in "Cool" and "Cold" classes, respectively in MN (Figure 2c, d).

At the third level (alt. $1082 \mathrm{~m}$ in MN and $1050 \mathrm{~m}$ in MG), the greater percentage of the THI values in MN and MG were found in "Hot" class during the hours 09:00-20:00 (Table 3). "Comfortable" and "Cool" classes were detected in $16.0 \%$ and $18.0 \%$ in MN and MG, respectively, during the above period. At night and morning (21:00-8:00 h), almost equal percentages of the THI values (about $69 \%$ ) were classed as "Comfortable" in both study regions (Figure $2 \mathrm{e}, \mathrm{f}$ ).

At the fourth level (alt. $1338 \mathrm{~m}$ in MN and $1334 \mathrm{~m}$ in MG), $57.2 \%$ and $47.9 \%$ of THI values were classed as "Comfortable" at MN and MG, respectively during the period from 09:00 to 20:00 $\mathrm{h}$ (Figure 2g, h).

For the rest period $(21: 00-08: 00 \mathrm{~h})$, the greater percentages of $\mathrm{THI}$ values $(72.4 \%$ in $\mathrm{MN}$ and $70.6 \%$ in MG) were lying in the "Comfortable" class.

The percentage sum of the classes "Hot" and "Very Hot" in average values was significantly different between the study regions for all the examined levels from 21:00 to 08:00 $\mathrm{h}$ and only in the fourth level from 09:00-20:00 $\mathrm{h}$ (Table 3). During this period, the differences of the above percentages between MG and MN took small values at the first, the second and the third level (they did not exceed $5.5 \%$ ).

Table 3. Percentages (\%) of the sum of classes "Hot" and "Very Hot" from 9.00 to $20.00 \mathrm{~h}$ and from 21.00 to $8.00 \mathrm{~h}$ in Gerania Mountains (MG) and mountainous Nafpaktia (MN)

\begin{tabular}{llllllllll}
\hline \multicolumn{7}{l}{ Percentage of the sum of classes "Hot" and "Very Hot" $(\%)$} \\
\hline Levels $^{\mathrm{y}}$ & $9: 00$ to $20: 00 \mathrm{~h}$ & $\mathrm{~g}$ & \multicolumn{7}{l}{ 21:00 to 8:00 $\mathrm{h}$} \\
\hline First & $96.1(1.2)^{\mathrm{x}}$ & $\mathrm{a}^{\mathrm{w}}$ & $90.6(6.6)$ & $\mathrm{a}$ & $37.6(4.9)$ & $\mathrm{a}$ & $10.5(5.7)$ & $\mathrm{b}$ \\
\hline Second & $83.7(4.9)$ & $\mathrm{a}$ & $87.9(4.7)$ & $\mathrm{a}$ & $24.5(2.4)$ & $\mathrm{a}$ & $10.1(3.9)$ & $\mathrm{b}$ \\
\hline Third & $82.0(5.4)$ & $\mathrm{a}$ & $83.6(5.2)$ & $\mathrm{a}$ & $28.9(2.1)$ & $\mathrm{a}$ & $15.2(4.0)$ & $\mathrm{b}$ \\
\hline Fourth & $48.8(6.7)$ & $\mathrm{a}$ & $37.9(5.4)$ & $\mathrm{b}$ & $12.7(0.8)$ & $\mathrm{a}$ & $6.8(1.1)$ & $\mathrm{b}$ \\
\hline
\end{tabular}

${ }^{2}$ The "Very Hot" class was appeared only at the altitudes $650 \mathrm{~m}$ and $676 \mathrm{~m}$ in MG and in MN, respectively.

${ }^{\mathrm{y}}$ First level: altitudes (alt.) $650 \mathrm{~m}$ in MG and $676 \mathrm{~m}$ in MN, Second level: alt. $850 \mathrm{~m}$ in MG and $862 \mathrm{~m}$ in MN,

Third level: alt. $1050 \mathrm{~m}$ in MG and $1082 \mathrm{~m}$ in MN, Fourth level: alt. $1334 \mathrm{~m}$ in MG and 1338m in MN.

${ }^{x}$ Mean (standard error of mean).

${ }^{w}$ Means within rows, separately for 09:00-20:00 $\mathrm{h}$ and 21:00-08:00 $\mathrm{h}$, followed by different letters are significantly different each from other after their angular transformation, according to two-sample $\mathrm{t}$ test at $\mathrm{p}<0.05$.

Therefore, it can be assumed that the two regions 'behaved' in the same way as regards to their thermal comfort conditions above "Comfortable". The significant difference of the previous percentage at fourth level, almost two-fold compared to $5.5 \%$, indicates that $\mathrm{MN}$ showed more favorable biometeorological conditions compared to MG at the previous level from 09:00 to 20:00 $\mathrm{h}$. This could be attributed to the fact that the plant cover density was considerably higher in MN compared to MG at the highest examined altitudes. Thus, there were more "open" sites in MG compared to $\mathrm{MN}$ where less amount of solar radiation reached ground surface (Larcher, 2003) resulting in lower temperature values (Morecroft et al., 1998). Nastos and Matzarakis (2007) reported heat stress conditions in Athens, by using the physiologically equivalent temperature index, for the previous hours (09:00 - 20:00 h) of the examined period of our study. As regards to the rest period (21:00-08:00 h), the sum of percentages "Hot" and "Very Hot" was significantly and consistently lower in $\mathrm{MN}$ compared to $\mathrm{MG}$, for the same level. Thus, $\mathrm{MN}$ presented more favorable biometeorological conditions in relation to MG during the previous period. 


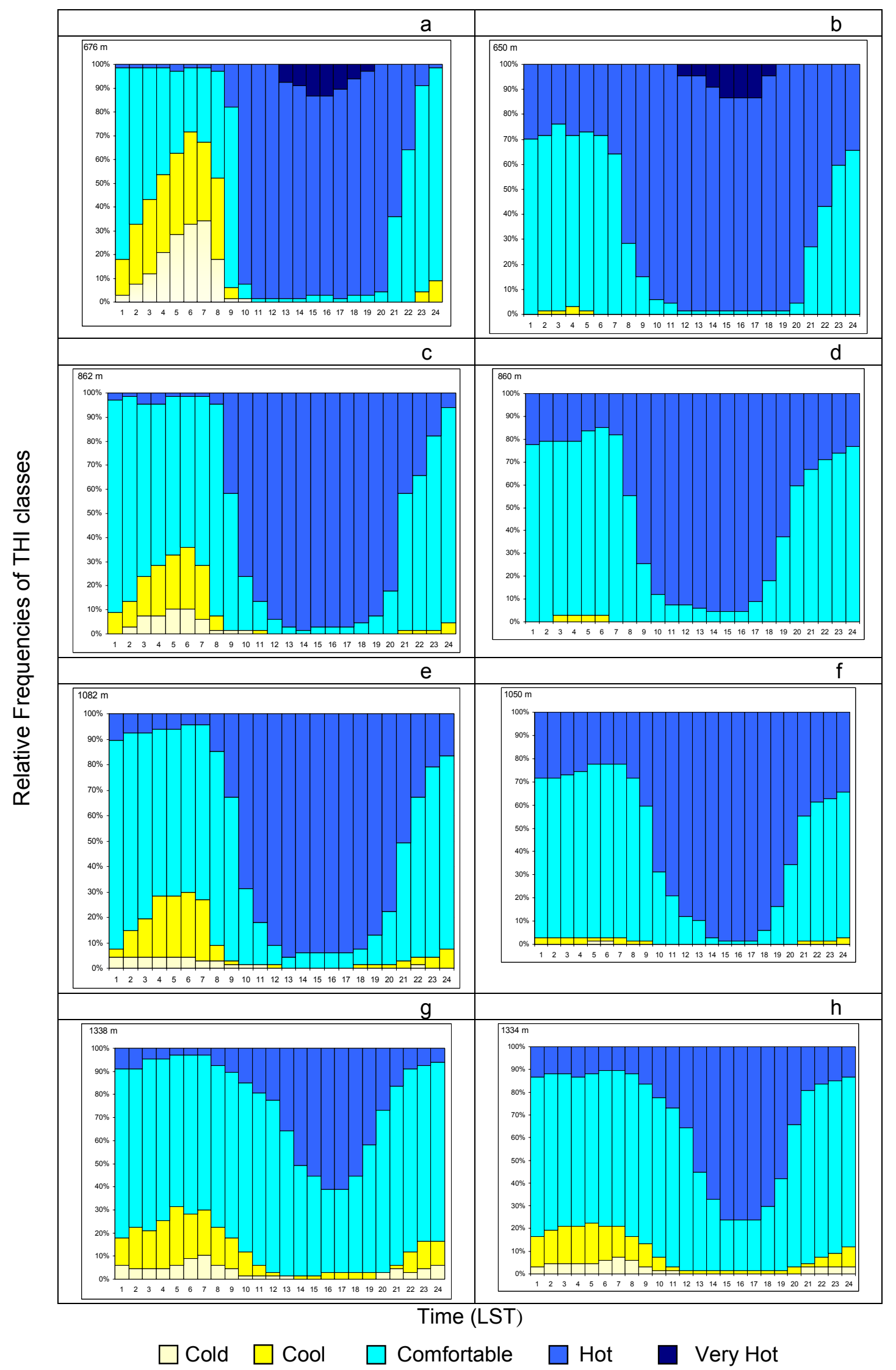

Figure 2. Relative frequencies of different categories of thermohygrometric index (THI) values on hourly basis at the mountainous Nafpaktia (a, c, e, g), and Gerania mountains (b, d, f, h) at different altitude levels from 23 June up to 28 August 2007. (LST: Local Standard Time $=$ Greenwich Meridian Time $+2 \mathrm{~h}$ ) 
The percentage difference took its greater value at the first level and as the altitude increased this value became progressively smaller.

The increased percentages of "Hot" and "Very Hot" classes in MG compared to MN for the same level, from 21:00 to 08:00 h, could be attributed merely to the "thermal effect" of the industrial areas of west Attica and of Korinthos nearby to MG. One of these areas, Elefsis, concentrates about $40 \%$ of the industrial activity of Greece (Kassomenos and Katsoulis, 2006). Additionally, MG has a relatively small distance from Athens which is an intensively urbanized city (Horbert et al., 1988; Philandras et al., 1999; Livada et al., 2002; Kassomenos and Katsoulis, 2006). As a consequence, the built up materials (cement, asphalt, etc) exist in a huge degree. Their rate of heat release during night time is slow as a result of the reduced rate of longwave radiative loss, of stored heat and of their thermal properties (Kassomenos and Katsoulis, 2006). Therefore, these materials rise the temperature of the surroundings.

The results of the various tests that have been performed with the neural network model for the prediction of $\mathrm{THI}$ at the fourth level of $\mathrm{MN}$ and $\mathrm{MG}$ are presented in Table 4. The coefficient of determination $\left(\mathrm{R}^{2}\right)$ of the measured THI values at the fourth level of both $M G$ and $M N$ versus the corresponding predicted values by the three prediction scenarios (T1, T2, T3) are also shown in the previous table. As can be seen, the predictions for the three scenarios give similar and satisfying results from 09:00 to 20:00 h. During the rest time of the day (21:00-08:00 h), however, and despite of the fact that the coefficient of determination has lower values, there is a noticeable difference between predictions for $M G$ and $M N$. This fact could be attributed partially to the different rate of the nocturnal radiative cooling under calm clear sky condition due to the change in the dominating plant species between the first and the fourth level in MN and MG (Table 1).

Table 4. Coefficients of determination $\left(R^{2}\right)$ and Mean Absolute Errors (MAE) of THI predictions of the fourth level based on data of the first level in Gerania mountains (MG) and mountainous Nafpaktia $(\mathrm{MN})$

\begin{tabular}{lllllllll}
\hline \multicolumn{2}{l}{ 9:00 to 20:00h } & \multicolumn{9}{c}{$21: 00$ to 8:00h } \\
\hline & MG & & MN & \multicolumn{3}{c}{ MG } & & MN \\
\hline & $R^{2}$ & $M A E$ & $R^{2}$ & $M A E$ & $R^{2}$ & $M A E$ & $R^{2}$ & $M A E$ \\
\hline T1 & 0.88 & 0.60 & 0.62 & 0.96 & 0.50 & 1.32 & 0.30 & 1.46 \\
\hline T2 & 0.83 & 0.67 & 0.64 & 0.94 & 0.50 & 1.34 & 0.35 & 1.40 \\
\hline T3 & 0.88 & 0.58 & 0.69 & 0.87 & 0.50 & 1.30 & 0.38 & 1.37 \\
\hline
\end{tabular}

The first level comprises the altitudes of $650 \mathrm{~m}$ and of $676 \mathrm{~m}$ in MG and MN, respectively. The fourth level comprises the altitudes of $1334 \mathrm{~m}$ and of $1338 \mathrm{~m}$ in MG and MN, respectively. T1, T2, T3: First, second and third scenario predictions at $p<0.01$.

\section{CONCLUSION}

From 09:00 to 20:00 h, mountainous Nafpaktia was found to be more suitable, in relation to Gerania mountains, from a biometeorological point of view, for tourist and recreation activities at altitudes of about $1340 \mathrm{~m}$. At the lower examined altitudes, for the same period, both study regions can be proposed for the above activities, during the examined summer months. The situation is different for the rest hours of the day (21.00:08:00), in which mountainous Nafpaktia clearly can be considered as a better destination than Gerania mountains, at all examined altitudes.

From 09:00 to 20:00 $\mathrm{h}$ at the highest examined altitudes of MG and MN, thermal comfort conditions as expressed by $\mathrm{THI}$ values can be predicted accurately by using artificial neural network model $(M L P)$ based on the temperature and humidity or THI conditions at the lowest examined altitudes. In addition, for the rest time of the day the use of the above model results in a noticeable prediction of thermal comfort conditions at the examined highest altitudes of MN and MG.

\section{ACKNOWLEDGMENT}

The authors would like to thank Dr. Ioannis Tsiros, Assist. Professor with the Division of Geological Sciences and Atmospheric Environment, Agricultural Univeristy of Athens for providing insights and useful comments. Thanks are also due to Mr. M. Pagonis, Technical Assistant for his help with the graphs.

\section{REFERENCES}

ASHRAE. (1966), Thermal comfort conditions, ASHRAE standard 55.66, New York. 
Barry L.G., (2001), Mountain weather and climate, Second Edition, Routledge, Taylor and Francis Group, New York, USA.

Beniston M., Dianz H.F. amd Brandley R.S., (1997), Climatic change at high elevation sites: an overview, Climate Change, 36, 233-251.

Chronopoulos K.I., Tsiros I.X., Dimopoulos I.F., Alvertos N., (2008), An application of artificial neural network models to estimate air temperature data in areas with sparse network of meteorological stations, Journal of Environmental Science and Health - Part A, 43, 1752-1757.

Friedland A.J., Boyce R.L., Vostral C.B., Herrick G.T., (2003), Winter and early spring microclimate within a mid-elevation conifer forest canopy, Agricultural and Forest Meteorology, 116,195-200.

Hellenic National Meteorological Service. (1999), Climate data of the stations of H.N.M.S., Direction of Climatology, Years 1955-1997, Athens, Greece, (in Greek).

Horbert B., Kircheorg A., Chronopoulou-Sereli A. and Chronopoulos J., (1988), Impact of Green on the Urban Atmosphere in Athens, Scientific Series of International Bureau Kernforschungsanlage Jülich $\mathrm{GmbH}$, Berlin, Germany.

Kamoutsis A., Matsoukis A., Charalampopoulos I. and Chronopoulou-Sereli A., (2007), Biometeorological conditions in mountainous communities and adjacent urban center in Greece by the use of indices: The case study of mountainous Nafpaktia district, In: Developments in Tourism Climatology, Matzarakis, A., de Freitas, C. R. and Scott, D. (Eds.), $3^{\text {rd }}$ International Workshop on Climate, Tourism and Recreation, Alexandroupolis, Greece 19-22 September, Commission on Climate, Tourism and Recreation, International Society of Biometeorology Freiburg, 144-149.

Kassomenos P.A. and Katsoulis B.D., (2006), Mesoscale and macroscale aspects of the morning Urban Heat Island around Atthens, Greece, Meteorology and Atmospheric Physics, 94, 209-218.

Larcher W., (2003), Physiological Plant Ecology, Fourth Edition, Springer Verlag, Germany.

Livada I., Santamouris M., Niachou K., Papanikolaou N. and Mihalakakou G., (2002), Determination of places in the great Athens area where the heat island effect is observed, Theoretical and Applied Climatology, 71, 219-230.

Manoli E., (2008), Investigation of bioclimatic conditions and perspectives of development in Gerania mountains. M.Sc. Thesis, Department of Sciences, Agricultural University of Athens Greece (in Greek with English abstract).

Matzarakis A., (2007), Climate, thermal comfort and tourism, In: Climate Change and TourismAssesment and Coping Strategies, Amelung, B., Blazejczyk, K., Matzarakis, A. (Eds.), Maastricht-Warsaw-Frieburg, 139-154.

Morecroft M.D., Taylor M.E. and Oliver H.R., (1998), Air and soil microclimates of deciduous woodland compared to an open site. Agricultural and Forest Meteorology, 90, 141156.

Nastos P.T. and Matzarakis A., (2008), Bioclimatic conditions, trends and variability at the University Campus of Athens, In: Proceedings of the $9^{\text {th }}$ Conference of Meteorology, Climatology and Atmospheric Physics, Department of Meteorology-Climatology, School of Geology, Aristotle University of Thessaloniki (Ed.) in collaboration with the Hellenic Meteorological Society, Thessaloniki, Greece 28-31 May 2008, 925-932 (in Greek).

Nepal K.S. and Chipeniuk R., (2005), Mountain tourism: Toward a Conceptual Framewok, Tourism Geographies, 7, 313-333.

Oliveira S. and Andrade H., (2007), An initial assessment of the bioclimatic comfort in an outdoor public space in Lisbon, International Journal of Biometeorology, 52, 69-84.

Philandras C.M., Metaxas D.A. and Nastos P.Th., (1999), Climate Variability and Urbanization in Athens, Theoritical and Applied Climatology, 63, 65-72.

Rumelhart D.E., Hinton G.E. and Williams R.J., (1986a), Parallel Distributed Processing Explorations in the Microstructure of Cognition, Rumelhart, D.E., McClelland, J.L., (Eds.), Vol. 1, MIT Press, Bradfords Books: Cambridge, MA, 318-362.

Rumelhart D.E., Hinton G.E. and Williams R.J., (1986b), Learning representations by back-propagating error, Nature, 323, 533-536.

Tang Z. and Fang J., (2006), Temperature variation along the northern and southern slopes of Mt. Taibai, China, Agricultural and Forest Meteorology, 139, 200-207.

Toy S., Yilmaz S. and Yilmaz H., (2007), Determination of bioclimatic comfort in three different land uses in the city of Erzurum, Turkey, Building and Environment, 42, 1315-1318.

Yilmaz S., Toy S. and Yilmaz H., (2007), Human thermal comfort over three different land surfaces during summer in the city of Erzurum, Turkey, Atmosfera, 20, 289-297. 